\title{
DETERMINAÇÃO DO PERÍODO CRÍTICO PARA PREVENÇÃO DA INTERFERÊNCIA DE PLANTAS DANINHAS NA CULTURA DE SOJA: USO DO MODELO "BROKENSTICK" 1
}

\author{
CLAUDIO A. SPADOTT0² ${ }^{2}$ DANIEL A.S. MARCONDES ${ }^{3}$; ALFREDO J.B. LUIZ ${ }^{4}$ e \\ CARLOS A.R. da SILVAS
}

RESUMO

\begin{abstract}
Visando a fornecer subsídios para programas de manejo de plantas daninhas em culturas agrícolas, foi conduzido um experimento de campo em Botucatu, SP. O objetivo foi determinar, através do procedimento estatístico de análise de regressão, o período critico para prevenção da interferência (PCPI) de plantas daninhas de folha larga na produtividade da cultura de soja. Foi utilizado o delineamento experimental em blocos casualizados, com 3 repetições. A cultura foi mantida na presença das plantas daninhas de folha larga
\end{abstract}

por diferentes períodos. O período crítico determinado foi de 21 a 30 dias após a emergência da cultura, segundo ajuste dos dados de produtividade ao modelo "Broken-Stick". No entanto, o período critico determinado indica que o controle das plantas daninhas pode ser realizado, uma única vez, através do uso de método momentâneo, sem efeito residual.

Palavras-chave: Modelos de regressão, controle, manejo, ecologia, Glycine max.

\section{ABSTRACT \\ Determining the critical period of weeds interference on soybean yield: use of broken-stick model}

This research is in support of weed management programs. A field experiment was carried out in Botucatu (São Paulo, Brazil), with the objective to determine the critical period of broadleaf weed interference on soybean, using statistical procedures of regression analysis. A randomized block design was used with 3 replications. The crop was kept weed infested for different periods. The critical period of

\section{INTRODUÇÃO}

Os programas de manejo de plantas daninhas são importantes no sentido da racionalização do seu controle em culturas agricolas. Para a implementação desses programas é weed interference determined by the "Broken-Stick" model was between 21-30 days after crop emergence. Broadleaf weeds in soybean crops can be controled with single use of remedial methods without residual effect.

Additional index words: Regression models, control, weed management, ecology, Glycine max.

imprescindível estudar os periodos de convivência possível entre as plantas daninhas e a planta cultivada.

Segundo Pitelli \& Durigan (1984), o período anterior a interferência (PAI) é aquele em que, a partir da emergência da cultura, esta pode conviver com as plantas daninhas sem

\footnotetext{
${ }^{1}$ Recebido para publicação em 04/04/94 e na forma revisada em 17/06/94. Trabalho realizado com suporte financeiro da FAPESP.

${ }^{2} \mathrm{Eng}^{\circ} \mathrm{Agr}^{\circ}, \mathrm{MSc}$, Pesquisador da EMBRAPAlCNPMA, Caixa Postal 69, Jaguariúna, SP 13820-000

${ }^{3} \mathrm{Eng}^{\circ} \mathrm{Agr}^{\circ}, \mathrm{PhD}$, Prof. Assistente da UNESP/FCA, Caixa Posta1 237, Botucatu, SP 18603-970

${ }^{4}$ Eng" Agr ${ }^{\circ}$, MSc, Pesquisador/Estatístico da EMBRAPA/CPAC, Caixa Posta1 08223, Brasilia, DF 733011-970

${ }^{5}$ Eng $^{\circ}$ Agr $^{\circ}$, Pós-graduando na UNESP/FCA, Rua Vita1 Brasil, 580, Botucatu, SP 18603-650
} 
reduções na sua produtividade; e o período total de prevenção da interferência (PTPI) é aquele em que, a partir da emergência da cultura, as plantas daninhas devem ser controladas para que a cultura possa manifestar todo seu potencial de produtividade. $\mathrm{O}$ intervalo compreendido entre esses dois periodos é o periodo critico para prevenção da interferência (PCPI).

Diversos fatores estão envolvidos na interação entre a cultura, a comunidade de plantas daninhas e o ambiente (Bleasdale, 1960; Blanco, 1972; Pitelli, 1985). Nesse processo interativo, os fatores mais facilmente controláveis, na prática, são a época e a extensão do período de convivência entre a cultura e as plantas daninhas.

Particularmente, quanto à comunidade de plantas daninhas, a sua composição específica assume grande importância. O desenvolvimento de herbicidas com maior especificidade possibilita o controle das plantas daninhas, subdividindo-as, pelo menos em dois grandes grupos, o das gramíneas e o das de folha larga, condicionando, assim, a composição da comunidade infestante.

Dentro do conceito de manejo das plantas daninhas, o conhecimento do periodo critico para prevenção da interferência é fundamental, e diversos trabalhos de pesquisa sobre o tema têm sido realizados: Knake \& Slife (1969), Blanco et al. (1973), Banentine (1974), Oliver et al. (1976), Coble \& Ritter (1978), Garcia et al. (1981), Maia et al. (1982), Durigan (1983), Rossi (1985), Harris \& Ritter (1987)e Velini (1989).

As diferentes metodologias usadas na análise estatística e interpretação dos dados contribuem para a grande variabilidade de informações sobre o assunto. A análise de variância, como é feita usualmente, pressupõe independência dos diversos tratamentos utilizados. No caso de série quantitativa de tratamentos com vários níveis (tratamentos estruturados), a análise da variância deve refletir a dependência entre os tratamentos, e, nesse caso, é necessário estudar a correspondência funcional.

Já os testes de comparações múltiplas requerem tratamentos não estruturados. Se os tratamentos de um experimento são estruturados, e são submetidos a testes de comparações múltiplas, informações úteis são ignoradas e conclusões erradas e sem sustentação estatística podem ser extraídas (Cousens, 1988).

Quando os tratamentos quantitativos têm mais de dois níveis é essencial considerar a equação de regressão (Pimentel Gomes, 1987). A escolha de um determinado modelo depende de critérios baseados no conhecimento prévio do fenômeno a ser estudado, no ajuste obtido e no objetivo do trabalho de pesquisa.

Em muitos trabalhos os dados têm sido comparados por meio de testes de médias (na grande maioria, Tukey e Duncan), que não são estatisticamente apropriados ao caso, e aceitam, por vezes, grandes perdas na produtividade. O uso de correpondência funcional, através de ajuste em equação de regressão, se bem aplicado, elimina esses problemas.

O modelo de Spillman-Mitscherlich, discutido por Pimentel Gomes (1987), tem sido utilizado na análise de dados em experimentos de adubação e está, segundo base teórica, adequado ao fenômeno biológico no caso de diferentes periodos de controle das plantas daninhas.
Entretanto, especificamente para a determinação dos periodos de convivência possível entre a cultura e as plantas daninhas, pode-se recorrer aos modelos de regressão segmentados, discutidos por Gallant \& Fuller (1973).

O modelo "broken-stick" utilizado por Colwell (1983) e Colwell et al. (1988), também com dados de experimentos de adubação, é um tipo especial de modelo segmentado, em que se tem duas retas, sendo que uma delas forma um platô.

Este trabalho foi realizado com o objetivo de determinar, através do procedimento estatístico de análise de regressão, o período critico para prevenção da interferência de plantas daninhas de folha larga na produtividade da cultura de soja.

\section{MATERIAL E MÉTODOS}

Experime nto de campo foi conduzido em Botucatu (São Paulo), no ano agrícola 1987/88. O clima da região é temperado úmido, com verões quentes. O solo na área do experimento é Terra Roxa Estruturada distrófica, situação de meia encosta em relevo ondulado, com textura muito argilosa, saturação em bases e acidez médias.

O preparo do solo foi convencional, com aração e gradagens. A última gradagem foi realizada logo antes da semeadura. Com base nos resultados da análise química do solo, foram feitas a calagem e a adubação. Esta foi efetuada no sulco de semeadura.

A operação conjunta de adubação e semeadura foi mecanizada. As sementes foram previamente inoculadas. A densidade populacional foi de cerca de 20 plantas de soja por metro linear. Foi utilizado o cultivar IAC-8, de porte alto, ciclo médio-tardio, hábito de crescimento determinado, que floresceu aos 55 dias e completou o ciclo aos 140 dias.

As eventuais gramíneas que emergiram na área do experimento foram eliminadas precocemente, em qualquer época do ciclo da cultura, com graminicida (sethoxydim) de aplicação pós-emergente.

As plantas daninhas que permaneceram na área do experimento foram exclusivamente as de folha larga, na grande maioria dicotiledôneas, exceção feita a trapoeraba (Commelina benghalensis). Assim, as principais espécies presentes foram: picão-preto (Bidens pilosa), picão-branco (Galinsoga parviflora) e guanxuma (Sida rhombifolia).

Os tratamentos foram constituídos de dois grupos complementares, segundo os critérios de convivência inicial e final entre a cultura e as plantas daninhas. Em um deles a cultura permaneceu na presença de plantas daninhas de folha larga, desde a emergência até diferentes estádios do seu ciclo de desenvolvimento, a saber: 0, 10, 20, 30, 40, 50 e 60 dias. Após isto, as plantas daninhas foram removid as das parcelas através de capinas, sendo mantidas sem infestação até a colheita da cultura.

Em outro grupo de tratamentos, a cultura permaneceu na ausência de plantas daninhas desde a emergência até 0 , 10, 20, 30, 40, 50 e 60 dias do seu ciclo. Após estes estádios, as plantas daninhas de folha larga que emergiram foram deixadas e conviveram com a cultura até a colheita.

O experimento no campo foi baseado no delineamento em blocos casualizados com três repetições. Cada parcela 
experimental foi constituída de seis linhas de semeadura, espaçadas de 0,6 m, com 4,0 m de comprimento. Como área útil de cada parcela foram consideradas as quatro linhas centrais, desprezando-se $0,5 \mathrm{~m}$ em cada extremidade, ficando $\operatorname{com} 7,2 \mathrm{~m} 2$.

$\mathrm{Na}$ colheita, foi apanhado manualmente o total de plantas de soja da área útil de cada parcela. Depois de passar por trilhadeiras mecânicas, foi pesada a produção de grãos. Os dados de produtividade da cultura, expressos em $\mathrm{kg} / \mathrm{ha}$, foram ajustados conforme modelos de regressão.

Os tratamentos, em que a cultura permaneceu por períodos iniciais crescentes na presença das plantas daninhas, foram usados para determinar a extensão do período inicial de convivência possível. Os tratamentos, em que a cultura permaneceu por periodos iniciais crescentes na ausência das plantas daninhas, serviram para determinar o período final de convivência possível.

A análise conjunta destes dois períodos forneceu informações para se determinar a época, a duração e o tipo do período crítico para prevenção da interferência das plantas daninhas de folhas largas na cultura de soja.

\section{RESULTADOS E DISCUSSÃO}

Na Tabela 1 estão os dados médios de produtividade da soja e de acúmulo de matéria seca das plantas daninhas.

Os dados de produtividade, variando com os diferentes períodos iniciais da cultura convivendo com as plantas daninhas, foram ajustados conforme o modelo de Spillman-Mitscherlich, resultando na equação: $\mathrm{Y}=2100,25-0,91.0,88^{-\mathrm{x}}$ $\left({ }^{\mathrm{R} 2}=0,62^{*}\right)$.

$\mathrm{O}$ ajuste dos dados de produtividade da soja, variando com os diferentes periodos finais da cultura convivendo com as plantas daninhas, resultou, segundo o modelo SpillmanMitscherlich, na equação: $\mathrm{Y}=2053,92-857,81 \cdot 0,94^{\mathrm{x}}$ $\left({ }^{\mathrm{R} 2}=0,66^{*}\right)$.

$\mathrm{Na}$ Figura 1 estão as equações e as curvas ajustadas com os dados de produtividade da soja, decompostos segundo os critérios de convivência inicial e final com as plantas daninhas, utilizando o modelo "broken-stick".

Segundo o critério de convivência inicial entre a cultura e as plantas daninhas, é possível observar (Figura 1) que a produtividade manteve-se estável até 30 dias do ciclo da cultura. Enquanto que, pelo critério de convivência final, a produtividade atingiu um patamar superior após 21 dias do ciclo (Figura 1).

Com as informações fornecidas pelo ajuste dos dados através do modelo "broken-stick", o período crítico para prevenção da interferência (PCPI), ou seja, o periodo no qual o controle das plantas daninhas de folha larga tem que ser realizado, foi de 21 a 30 dias após a emergência da cultura de soja.

É importante destacar que o período inicial de convivência possível (30 dias) estendeu-se até após o começo do período final (21 dias). Isto confere uma característica diferenciada ao período critico determinado. $\mathrm{O}$ controle poderia ser feito através de método momentâneo, sem efeito residual, como herbicida de aplicação pós-emergente, cultivador, etc, utilizado uma única vez, desde que dentro do período crítico.
TABELA 1 - Resultados médios da produtividade da cultura de soja e do acúmulo de matéria seca das plantas daninhas de folha larga, nos diferentes períodos de convivência. Botucatu (SP), 1987/88.

\begin{tabular}{|c|c|c|}
\hline 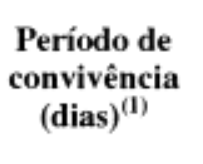 & $\begin{array}{c}\text { Produtividade } \\
\text { da soja } \\
(\mathrm{kg} / \mathrm{ha})\end{array}$ & $\begin{array}{c}\text { Acúmulo de } \\
\text { matéria seca das } \\
\text { plantas daninhas } \\
\left(\mathrm{g} / \mathrm{m}^{2}\right)\end{array}$ \\
\hline $0^{(2)}$ & 2156,5 & 0,0 \\
\hline $0-10$ & 2088,4 & 0,2 \\
\hline $0-20$ & 1996,3 & 1,9 \\
\hline $0-30$ & 2106,5 & 3,9 \\
\hline $0-40$ & 1917,1 & 13,9 \\
\hline $0-50$ & 1455,4 & 74,1 \\
\hline $0-60$ & 1448,9 & 71,4 \\
\hline $0-140^{(3)}$ & 1241,9 & 69,0 \\
\hline $10-140$ & 1397,8 & 21,3 \\
\hline $20-140$ & 2000,9 & 20,5 \\
\hline $30-140$ & 1910,6 & 8,2 \\
\hline $40-140$ & 1932,4 & 10,2 \\
\hline $50-140$ & 1940,7 & 6,4 \\
\hline $60-140$ & 2065,7 & 6,7 \\
\hline F trat. & $5,5^{\circ}$ & \\
\hline C.V.(\%) & 12,4 & \\
\hline
\end{tabular}

(1) Dias após a emergència da cultura

(2) Sem plantas daninhas durante todo o ciclo

(3) Colheita da cultura (140 dias)

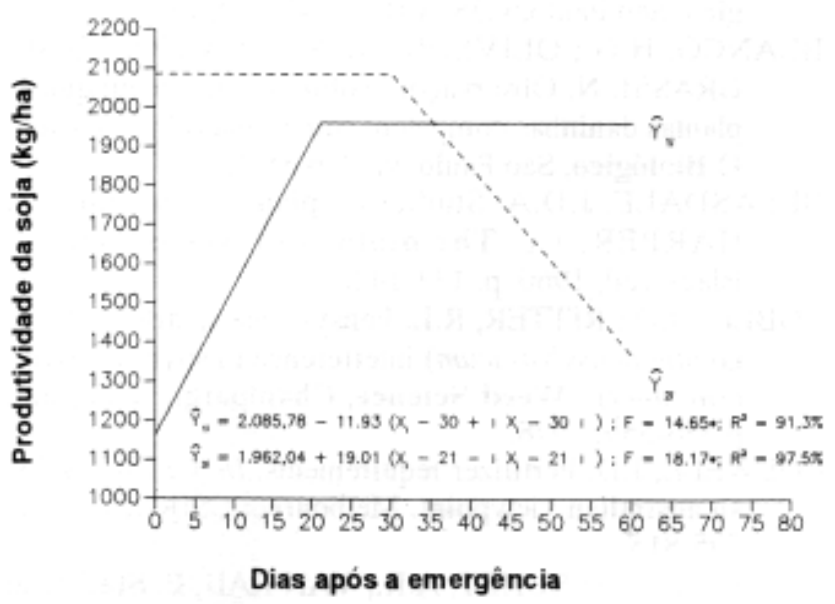

FIG. 1 - Representaçâo das curvas ajustadas com os dados de produtividade da soja decompostos segundo critérios de convivência inicial $\left(\hat{\mathbf{Y}}_{1 i}\right)$ e final $\left(\hat{\mathbf{Y}}_{2 i}\right)$ com as plantas daninhas de folha larga, utilizando o modelo "broken-stick". 
Através de estudos de correlação entre os dados de produtividade da soja e de acúmulo de matéria seca das plantas daninhas de folha larga (Tabela 1), foi determinado o coeficiente $\mathrm{R}=-0,99^{*}$, no caso do critério de convivência inicial. $\mathrm{O}$ coeficiente de correlação foi $\mathrm{R}=-0,82 *$ para os dados, segundo o critério de convivência final.

Os dados de acúmulo de matéria seca das plantas daninhas por ocasião da colheita da cultura de soja. Nos diferentes periodos finais de convivência (Tabela 1), evidenciam que os valores menores ocorreram quando o controle das plantas daninhas foi após 20 dias do ciclo da cultura.

A seguir são apresentadas as conclusões do trabalho:

1. O modelo "broken-stick" pode ser usado na determinação do período inicial e do período final de convivência possível entre a cultura e as plantas daninhas e, conseqüentemente, na determinação do período critico para prevenção da interferência.

2. O periodo critico para prevenção da interferência (PCPI) das plantas daninhas de folha larga foi de 21 a 30 dias do ciclo da cultura de soja. No entanto, este periodo critico indica que o controle das plantas daninhas pode ser feito, uma única vez, através do método momentâneo, sem efeito residual.

\section{AGRADECIMENTOS}

Ao Dr. Jeffrey D. Colwell, CSIRO, Austrália, ao Prof. Dr. Robinson A. Pitelli, FCAV/UNESP, Jaboticabal, e ao Dr. Domingos A. Oliveira, Instituto Biológico, Campinas, pelas valiosas contribuições.

\section{LITERATURA CITADA}

BARRENTINE, W.L. Common cocklebur competition in soybeans. Weed Science, Champaign, v.22, n.6, p.600-603, 1974.

BLANCO, H.G. A importância dos estudos ecológicos nos programas de controle de plantas daninhas. O Biológico, São Paulo, v.38, n.10, p.343-350, 1972.

BLANCO, H.G.; OLIVEIRA, D.A.; ARAÚJO, J.B.M.; GRASSI, N. Observações sobre o período em que as plantas daninhas competem com a soja (Glycine max). $\mathbf{O}$ Biológico, São Paulo, v.39, p.31-35, 1973.

BLEASDALE, J.D.A. Studies on plant competition. In: HARPER, J.L. The biology of weeds. Oxford: Blackwell, 1960. p. 133-142.

COBLE, H.D.; RITTER, R.L. Pensylvania smarteed (Polygonum pensylvanicum) interference in soybeans (Glycine $\max$ ). Weed Science, Champaign, v.26, n.6, p.556-559, 1978.

COLWELL, J.D. Fertilizer requirements. In: CSIRO. Soils: an australian viewpoint. Melbourne: CSIRO, 1983. p. 795815.

COLWELL, J.D.; SUHET, A.R.; VAN RAID, B. Statistical procedures for developing general soil fertility models for variable regions. Australia: CSIRO, 1988. 68p. (CSIRO. Division of Soils. Divisional Report, 93).
COUSENS, R. Misinterpretation of results in weed research through inappropriate use of statistics. Weed Research, Edinburgh, v.28, p.281-289, 1988.

DURIGAN, J.C. Matocompetição e comportamento de baixa dose de herbicidas na cultura da soja (Glycine max). Piracicaba: ESALQ/USP, 1983. 163p. Tese de Doutorado.

GALLANT, A.R.; FULLER, W.A. Fitting segmented polynomial regression models whose join points have to be estimated. Journal of the American Statistical Association, v.68, n.341, p.144-147, 1973.

GARCIA, A.; GAZZIERO, D.L.P.; TORRES, E. Determinação do período critico de competição de ervas daninhas com a cultura de soja. In: RESULTADOS DE PESQUISA DE SOJA, Lo nd rina: EMBRAPA/ CNPSo, 1981, Anais, p. 140-145.

HARRIS, T.C.; RITTER, R.L. Giant green foxtail (Setaria viridis var. major) and fall panicum (Panicum dichotomiflorum) competition in soybeans (Glycine max). Weed Science, Champaign, v.35, p.663-668, 1987.

KNAKE, E.L.; SLIFE, F.W. Effect of time of giant foxtail removal from corn and soybeans. Weed Science, Champaign, v.17, p.281-283, 1969.

MAIA, A.C.; REZENDE, A.M.; LACA-BUENDIA, J.P.C. Período crítico de competição de uma comunidade natural de plantas daninhas com a cultura da soja (Glycine max) no Triângulo Mineiro. In: SEMINARIO NACIONAL DE PESQUISA DE SOJA, 2,1982, Londrina. Anais. Londrina: EMBRAPA/CNPSo, 1982. p.370-380.

OLIVER, L.R.; FRANS, R.E.; TALBERT, R.E. Field competition between tall momingglory and soybeans. I- Growth analysis. Weed Science, Champaign, v.24, n.5, p.482-488, 1976.

PIMENTEL GOMES, F. A estatística moderna na pesquisa agropecuária. Piracicaba: POTAFOS, 1987. 160p.

PITELLI, R.A. Interferência de plantas daninhas em culturas agrícolas. Informe Agropecuário, Belo Horizonte, v.11, n.129, p.16-27, 1985.

PITELLI, R.A.; DURIGAN, J.C. Terminologia para períodos de controle e de convivência das plantas daninhas em culturas anuais e bianuais. In: CONGRESSO BRASILEIRO DE HERBICIDAS E PLANTAS DANINHAS, 15, 1984, Belo Horizonte. Resumos. Belo Horizonte: SBHED, 1984.p.37.

ROSSI, C.A. Efeitos de periodos de controle e de convivência das plantas daninhas na cultura da soja (Glycine max). FCAV/UNESP, Jaboticabal: FCAV/ UNESP, 1985. 49p. Trabalho de Graduação.

VELINI, E.D. Avaliação dos efeitos de comunidades infestantes naturais controladas por diferentes periodos sobre o crescimento e produtividade da cultura da soja (Glycine max). Jaboticabal: FCAV/UNESP, 1989. 